Article

\title{
Internalization of Negative External Cost of Logistics and Incentive Mechanism
}

\author{
Zhanzhong Wang *,+, Zhouling Tsai ${ }^{\dagger}$, Jing Fu ${ }^{+}$and Guangdong Tian \\ School of Transportation, Jilin University, Changchun 130022, China; caizl15@mails.jlu.edu.cn (Z.T.); \\ fujing13@mails.jlu.edu.cn (J.F.); tiangd2013@163.com (G.T.) \\ * Correspondence: wangzz@jlu.edu.cn; Tel.: +86-139-0431-6393 \\ + These authors contributed equally to this work.
}

\begin{abstract}
The implementation of green logistics can reduce the increasingly serious environmental damage and improve the operating efficiency of logistics enterprises. In this paper, through quantitative calculation of logistics negative external costs, including traffic accidents, atmospheric pollution, noise pollution, and pollution caused by packaging, we build accounting standards to calculate the negative external cost of logistics enterprises that mainly generate pollution from transportation and packaging. Then, assuming the impetus provided by government implementing incentive mechanisms in a free market economy, we establish a 'Logistics Negative External Cost Internalizing' model, which quantitatively analyzes the relationships among freight rate, freight volume, investment of enterprise for implementing green logistics, and the subsidy given by government, under the comparison of the two modes 'enterprise operates first' and 'government subsidizes first'. The results show that the introduction of 'government subsidizes first' incentive mechanism and increasing freight rate are helpful in promoting the process of logistics market greening.
\end{abstract}

Keywords: green logistics; negative externality of logistics; internalization of logistics negative external cost; incentive mechanism

\section{Introduction}

The value created by logistics occupies an important position in China's national economy. From 2000 to 2015 the average annual growth rate of China's social logistics was about $20 \%$, far greater than the growth of the national economy. As the natural environmental destruction caused by logistics is worsening, China and other countries around the world for their own logistics industries have developed corresponding cost accounting standards and analysis patterns. However, the damage to the ecological environment and natural resources produced in logistics activities have not been included in these logistics cost accounting systems. Researchers have carried out a great deal of work on the negative external impacts of logistics, basing much of this research on studies of the negative impacts on the environment. Research into the external cost of logistics is mainly focused on transportation, and the mechanism of internalizing external cost is mainly focused on the implementation of taxation.

Currently, scholars are demonstrating the necessity of internalizing the negative external cost of logistics from various aspects; the vast majority of them either theoretically or qualitatively analyze the issue of negative external cost internalization of logistics.

Johansson analyzed the externality cost of traffic congestion and constructed a congestion tax model after analyzing and calculating the social net income of various road users [1].

Van Woensel quantified the dynamic impact of road vehicles on the environment, and suggested that a model built at a constant speed on a particular road could allow for an assessment of emissions and a more effective measure of cost and negative impacts [2]. 
Kawase and Matsuoka have pointed out that Japan has enacted a new environmental tax plan in 2004 in which it is regulated that residents of every household in Japan will be subject to annual environmental taxes of 3,000 yen [3].

Jakob noticed that although negative external costs are taken into account, they are difficult to calculate. He used New Zealand as an example to calculate the total cost of private transport and public transport, and evaluated the externalities and internalities of the transportation costs [4].

Lemp analyzed and estimated the source of the negative external cost in transport, the results showing that the external cost of light trucks is much higher than that of passenger cars [5].

Lee taking the Large-Scale Network in the Asia-Pacific Region as a case study, have proposed the design of a sustainable logistics network based on stochastic programming in an uncertain environment, but only minimized the total cost of logistics [6].

To incorporate environmental management into everyday decision-making, Ubeda introduced variables in the vehicle minimization path that satisfy green criteria while also meeting efficiency goals [7].

Scholars such as Marchet have researched and compiled a number of related articles in which discuss the significance of sustainable development in logistics enterprise decision-making. However, most of the research in Archet's compendium was mainly based on case analysis and investigation and rarely involved simulation analysis and modeling research [8].

Lui analyzed the necessity of calculating and including negative externalities into total costs, and established a distribution network design model with consideration of negative externalities produced by distribution transportation [9].

Mesa-Arango researched the benefits of in-vehicle consolidation in increasing truck payload utilization, as well as reducing the negative externalities caused by freight transportation [10].

Africa's externality costs were included in a logistics measurement system when Havenga discussed this issue and found that transport costs suffer a great pressure from the oil price and the internalization of externality costs. Also established was a logistics costs model incorporating externality costs based on a gravity-oriented freight flow model, where it was found that national logistics costs can be reduced more easily as compared to company-level logistics on the condition of good coordination of company-level transport [11].

Lera-Lopez adopted both double-hurdle and Moulton's models to evaluate the willingness of populations who live next to roads to pay for the negative externalities costs generated by logistics activities [12].

Fumasoli established an impact model to determine the effects of the characteristics of freight trains on capacity consumption in mixed traffic railway networks, the result shows that the use of freight trains can reduce the relative capacity consumption of freight trains and can reduce freight transport negative externalities [13].

Meersman analyzed how to mitigate negative externalities associated with land-based transport by taking a micro-research approach and proved that road pricing has a potential impact on the cost function of logistics [14].

The cost consumptions of logistics activities can be truly reflected, as we figure the damage caused by logistics activities on the environment and natural resources into the logistics cost accounting system. Nevertheless, logistics negative externalities have not been quantitatively accounted for, since there are a variety of factors contributing to them and the statistics are hard to come by. Therefore, there are a significant number of enterprises operating with high pollution and high emissions despite repeated prohibitions, complicating the process of environmental governance.

Approaches to reducing logistics externalities mainly include laws, regulations, taxation, finance, fiscal subsidies and logistics technology standards, with their rich theory and lesser amount of quantitative analysis. Thus, taking logistics enterprises as a case, in this paper we quantitatively calculate the negative external cost and analyze the incentive mechanism quantifiably. In the case of government incentive mechanisms, we establish a model with two modes, including 'enterprise operates first' and 'government subsidizes first', and account for the negative externalities of logistics enterprises in which freight is the main business. 


\section{Negative external costs accounting}

Marshall and Pigou put forward the concept of externality in the early 20th century. As applied in the field of logistics, 'externality' mainly refers to the fact that logistics activities additionally have negative impacts on other individuals' interests. The negative externalities of transportation and distribution generally include various damage, such as pollution emissions producing by conveyances, noise, traffic jams and accidents, etc. Negative externalities of warehousing mainly embody environmental pollution arising from bad warehouse management, including toxic and harmful gases leaking and the damage or rot of cargoes. Negative externalities of handling and hauling that are caused by the operation of related machineries include noise, dust, waste, etc. Packaging negative externalities usually refer to white pollution caused by packaging materials and resources wasted because of excessive packaging. But due to the imperfection of current statistical accounting systems, enterprises' have usually not taken the responsibility for these non-market costs, and thus it is extremely difficult for logistics markets to optimize resource allocation.

According to negative external logistics cost quantitative calculations, enterprises can set freight rates reasonably, and the government can formulate appropriate environmental policies as well. This can impel enterprises to take on their corresponding social responsibilities. In this paper, the negative external logistics cost accounting is divided into air pollution cost accounting, traffic accident cost accounting, traffic congestion cost accounting, noise pollution cost accounting, and negative external cost accounting of packaging.

\subsection{Air pollution cost accounting}

This article selected the freight transportation enterprise, and only considered freight vehicle emissions. By improving Baoqiang Xia's [15] calculation formula of road transport emissions, the freight vehicle emissions calculation formula can be obtained:

$$
Q_{W k}=\sum_{i=1}^{n}\left(N_{i}\left(\frac{Q_{i}}{\overline{q_{i}}}\right) F_{i k}\right)
$$

where $k$ represents the different pollutant categories $(k=1,2,3$, these pollutants being CO, NOx and $\mathrm{CH}), i$ for the vehicle type $(i=1,2 \ldots n), Q_{W k}$ for total pollutants emissions of the class $k$ pollutant, $N_{i}$ for car ownership of the type $i$ vehicle, $Q_{i}$ for the transport turnover volume of the type $i$ vehicle, $\overline{q_{i}}$ for the average capacity of the type $i$ vehicle, $F_{i k}$ for the average emission factor of the type $i$ vehicle that emits the class $k$ pollutant. The value of the emission factor refers to Table 1.

Table 1. Different types of vehicle emission factors.

\begin{tabular}{|c|c|c|c|c|}
\hline Type of vehicle & $\begin{array}{c}\mathrm{CO} \\
\text { emission } \\
\text { factor }\end{array}$ & $\begin{array}{c}\text { NOX } \\
\text { emission } \\
\text { factor }\end{array}$ & $\begin{array}{c}\mathrm{CH} \\
\text { emission } \\
\text { factor }\end{array}$ & Vehicle parameters \\
\hline $\begin{array}{l}\text { Light gasoline- } \\
\text { truck } 1\end{array}$ & 23.0 & 6.0 & 6.5 & Vehicle's full weight $\leq 6000$ pounds \\
\hline $\begin{array}{l}\text { Light gasoline- } \\
\text { truck } 2\end{array}$ & 20.0 & 12.5 & 2.5 & $\begin{array}{l}\text { Vehicle's full weight } \\
\text { between } 6001 \text { and } 8500 \text { pounds }\end{array}$ \\
\hline Light diesel-truck & 2.0 & 4.0 & 1.5 & Vehicle's full weight $\leq 8500$ pounds \\
\hline $\begin{array}{c}\text { Heavy-duty } \\
\text { gasoline vehicle }\end{array}$ & 10.6 & 2.1 & 1.3 & $\begin{array}{c}\text { Vehicle's full weight }>8500 \text { pounds, } \\
\text { or gross weight of equipment }>6000 \text {, } \\
\text { or the front windward area of the } \\
\text { cab }>6000 \text { square feet }\end{array}$ \\
\hline $\begin{array}{l}\text { Heavy-duty } \\
\text { diesel vehicle }\end{array}$ & 0.5 & 1.0 & 0.3 & $\begin{array}{l}\text { Vehicle's full weight }>8500 \text { pounds, } \\
\text { or gross weight of equipment }>6000 \text {, }\end{array}$ \\
\hline
\end{tabular}


or the front windward area of the cab $>6000$ square feet

We use the atmospheric pollution discharge standards in 'regulation of discharge pollutant standards' of China for reference. The air pollution negative external cost calculation formula is

$$
C_{a}=\sum_{k=1}^{3} E_{k} Q_{W k}
$$

where $C_{a}$ is the cost of pollutant discharge and $E_{k}$ is the unit external cost of the class $k$ pollutant.

\subsection{Traffic accident cost accounting}

The current measurements of traffic accident cost include the 'traffic accident model' and 'accident comprehensive economic loss measurement model' [16]. This paper comprehensively considered the research achievements of predecessors and data availability, then adopted the improved method of 'willingness to pay'. The traffic accident cost calculation formula is

$$
C_{s}=I_{c}+D_{c} Q
$$

where $C_{s}$ is the cost of the traffic accident, $I_{c}$ is the indirect loss cost of unit personnel, and $I_{c}$ comprises the labor value loss of the casualty, the spirit loss of a casualty's close relative, and the consumption loss of social service agencies [17]. Also, $D_{\mathrm{c}}$ is the direct cost of unit property loss[18]

$$
D_{c}=\frac{T_{z} \times \gamma}{Q_{q}}
$$

where $T_{z}$ is the loss caused by national traffic accidents and $\gamma$ is the freight transport turnover on the percentage of total passenger travel and freight transport turnover all over China; $Q_{q}$ is the total freight transport turnover of China. Both $I_{c}$ and $D_{c}$ are represent the average of which the loss under unit turnover, and $Q$ for the freight transport turnover of a given enterprise.

\subsection{Noise pollution cost accounting}

The impact of traffic noise is extensive and difficult to calculate; thus it is hard to calculate the loss caused by noise pollution. With reference to the European average noise pollution cost [19], the calculation formula for the average noise pollution cost of China is:

$$
C_{n}=C_{u n} \times \frac{\rho_{1}}{\rho_{u}} \frac{G_{1}}{G_{u}} \times R_{u} \times Q
$$

where $C_{n}$ is the loss of noise pollution and $C_{u n}$ is the average loss of noise pollution in Europe. $\rho_{1}$ and $G_{1}$, respectively, represent the population density and $G D P$ in a given area. $\rho_{u}$ and $G_{u}$, respectively, represent the population density and GDP in Europe. $R_{u}$ is the euro exchange rate for the $R M B$.

\subsection{Traffic congestion cost accounting}

Now traffic congestion cost accounting is usually concentrated on urban road passenger transport, but we focus on highway freight transportation. Therefore, traffic congestion loss in urban distribution is ignored in this paper. 
As the materials of logistics packaging mainly consist of plastics, wood packing and polyfoam, this paper employs defensive expenditures to calculate the processing cost of the discarded packaging materials. The calculation formula is

$$
C_{B}=\sum_{m=1}^{n} B_{m} M_{m}\left(1-\theta_{m}\right)
$$

where $C_{B}$ is the negative external cost of packaging And the subscript $m$ denotes the category of packing material (such as plastic, wood and polyfoam, $m=1,2, \ldots, n$ ). $B_{m}$ is the unit processing cost of the type $m$ packing material, $M_{m}$ is its unit mass, and $\theta_{m}$ is its recoverability rate.

To sum up, this paper takes $C$ to represent the logistics negative external costs of freight transportation enterprise, the calculation formula for $C$ being

$$
C=C_{a}+C_{s}+C_{n}+C_{B}
$$

\section{Logistics external cost internalization and incentive mechanism modelling}

Enterprises prefer lower costs, a fact that hinders the implementation of high-cost green logistics. Only when the government regulates the economy can we solve the question of market failure in developing green logistics. To encourage enterprises to adopt green logistics, we internalize the cost of logistics negative external cost, then analyze the incentive mechanism under government intervention.

\subsection{Problem description}

3.1.1. Assumptions of the model.

There are two kinds of full-scale enterprises, enterprises $x$ and enterprises $y$, of which enterprises $x$ are green logistics enterprises and enterprises $y$ are traditional logistics enterprises, both in the condition of a perfectly competitive market. The amounts of environmental taxation and government subsidies are calculated according to the logistics negative external cost. Also, government administration costs are ignored, which means all environmental taxations from enterprises y collected by the government are subsidies going to enterprises $\mathrm{x}$ for implementing green logistics. The production of freight transportation satisfies the production function of 'Cobb-Douglas', under the circumstance that pursuing maximum economic benefit is the target of all enterprises.

\subsubsection{Parameter specification.}

All parameters of the model refer to Table 2.

Table 2. Parameter definition and specification

\begin{tabular}{cl}
$\begin{array}{c}\text { Parameter } \\
\text { symbolic }\end{array}$ & Parameter explanation \\
\hline \multicolumn{4}{c}{} & $P_{0}$ for the freight rate before policies changed \\
& $P_{x}$ for the equilibrium freight rate of enterprises $x$ after implementing green \\
& logistics \\
& $P_{y}$ for the equilibrium freight rate of enterprises $y$ \\
& $P$ for the balanced freight rate of the two types enterprises in the complete market \\
\hline & $Q_{0}$ for the freight volume of each enterprise before policy changed \\
& $Q_{x}$ for the balanced freight volume of enterprises $x$ after implementing green \\
& $\operatorname{logistics}$ \\
$Q_{y}$ for the balanced freight volume of enterprises $y$ after policy changed
\end{tabular}




\begin{tabular}{cl}
\hline$A$ & $\begin{array}{l}A_{x} \text { for technical level of enterprises } x \text { after implementing green logistics } \\
A_{y} \text { for technical level of enterprises } y \text { without implementing green logistics }\end{array}$ \\
\hline$X$ & The amount of labor that the enterprise invests \\
\hline$Y$ & The amount of capital invested by the enterprise \\
\hline$\alpha$ & The elastic coefficient of manpower output \\
\hline$\gamma$ & The elastic coefficient of capital output \\
\hline$a$ & The amount of government subsidies or punishments to the enterprise \\
\hline$C$ & The amount of capital for implementing green logistics invested by enterprise $x$ \\
\hline
\end{tabular}

\subsection{Scheme of model establishment}

Figure 1 shows the framework of this paper: how to construct the internalization of the external cost model. According to the assumptions and under the regulation of government, the two types of enterprises $x$ and enterprises $y$ maneuver in a perfect competitive environment, finally leading to an equilibrium freight rate.

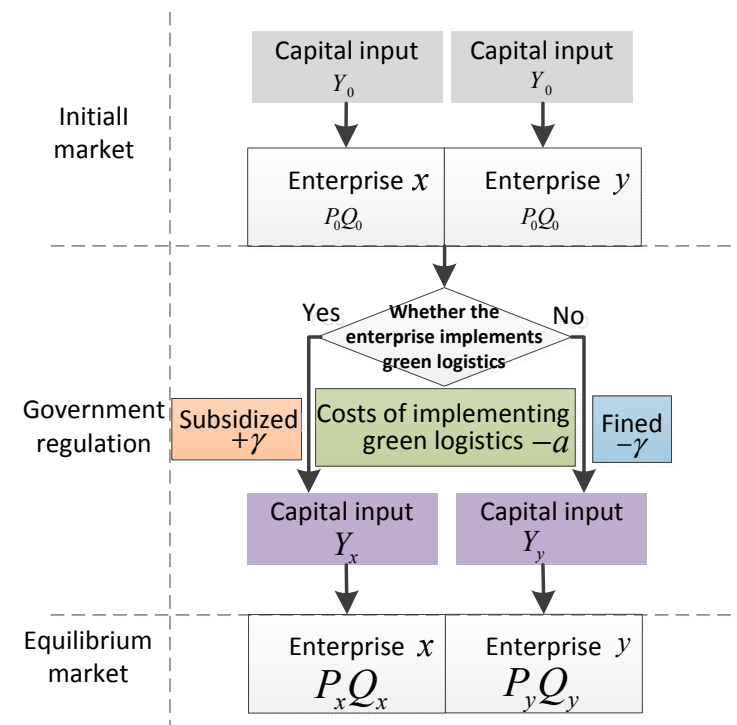

Figure 1. Model Specification of negative external costs internalization

\subsection{Model establishment}

The priority that government assigns in the distribution of subsidies to enterprises determines the two modes of the logistics negative external cost internalizing model: 'enterprise operates first' and 'government subsidizes first'.

\subsubsection{Enterprise operates first}

In this mode, enterprise $x$ invests $a$ yuan into implementing green logistics, so that the capital for enterprise operation is $Y-a$. Enterprise y needs to pay $\gamma$ yuan for environmental tax, and then the capital for enterprise operating is $Y-\gamma$. By government regulation, the competitive market levels off, the objective function meeting the total revenue no less than the total revenue that without government regulation, a condition that is given by

$$
\left[P_{x} Q_{x}+\gamma-C_{x}-(Y-a)\right]+\left[P_{y} Q_{y}-(Y-\gamma)\right] \geq 2 P_{0} Q_{0}-2 Y
$$


After compilation and transition, the critical function is given by

$$
P_{x} Q_{x}+2 \gamma-C_{x}+a+P_{y} Q_{y}=2 P_{0} Q_{0}
$$

Freight volume $Q$ meets 'Cobb-Douglas' production function, that is $Q=A X^{\alpha} Y^{\beta}$, there is a correlativity between negative external cost and freight volume, so we simplified the formula as $C=K Q$. Under the equilibrium market, the freight rate is unified. Function is given by

$$
\left\{\begin{array}{l}
Q_{x}=A_{x} X^{\alpha}(Y-a)^{\beta} \\
Q_{y}=A_{y} X^{\alpha}(Y-\gamma)^{\beta} \\
C_{x}=K Q_{x} \\
P_{x}=P_{y}=P
\end{array}\right.
$$

By the combination of (9) and (10), the relation between $P, a$ and $\gamma$ can be expressed by

$$
P A_{x} X^{\alpha}(Y-a)^{\beta}+2 \gamma-K A_{x} X^{\alpha}(Y-a)^{\beta}+a+P A_{y} X^{\alpha}(Y-\gamma)^{\beta}=2 P_{0} Q_{0}
$$

Reforming the formula $Q_{x}=A_{x} X^{\alpha}(Y-a)^{\beta}, a$ can be expressed by

$$
a=Y-\left(\frac{Q_{x}}{A_{x} X^{\alpha}}\right)^{\frac{1}{\beta}}
$$

Then according to (9), (10) and (12), the relationship between $P, Q_{x}$ and $\gamma$ can be expressed by

$$
P Q_{x}+2 \gamma-K Q_{x}+Y-\left(\frac{Q_{x}}{A_{x} X^{\alpha}}\right)^{\frac{1}{\beta}}+P A_{y} X^{\alpha}(Y-\gamma)^{\beta}=2 P_{0} Q_{0}
$$

Reforming the formula $Q_{y}=A_{y} X^{\alpha}(Y-\gamma)^{\beta}, \gamma$ can be expressed as

$$
\gamma=Y-\left(\frac{Q_{y}}{A_{y} X^{\alpha}}\right)^{\frac{1}{\beta}}
$$

Then according to (9), (13) and (14), the relationship between $P, Q_{x}$ and $Q_{y}$ can be expressed by

$$
P Q_{x}+2\left(Y-\left(\frac{Q_{y}}{A_{y} X^{\alpha}}\right)^{\frac{1}{\beta}}\right)-K Q_{x}+Y-\left(\frac{Q_{x}}{A_{x} X^{\alpha}}\right)^{\frac{1}{\beta}}+P Q_{y}=2 P_{0} Q_{0}
$$

\subsubsection{Government subsidizes first}

In this mode, when enterprise $x$ invests $a$ yuan in implementing green logistics, and gain government subsidies of $\gamma$ yuan as well, then the capital for enterprise operating is $Y-a+\gamma$. The capital for enterprise operations is still $Y-\gamma$. As above, the objective function is given by

$$
\left[P_{x} Q_{x}-C_{x}-(Y-a+\gamma)\right]+\left[P_{y} Q_{y}-(Y-\gamma)\right] \geq 2 P_{0} Q_{0}-2 Y
$$

After compilation and transition, the critical function is given by

$$
P_{x} Q_{x}-C_{x}+a+P_{y} Q_{y}=2 P_{0} Q_{0}
$$

The relationship between freight volume and freight rate can be expressed by 


$$
\left\{\begin{array}{l}
Q_{x}=A_{x} X^{\alpha}(Y-a+\gamma)^{\beta} \\
Q_{y}=A_{y} X^{\alpha}(Y-\gamma)^{\beta} \\
C_{x}=K Q_{x} \\
P_{x}=P_{y}=P
\end{array}\right.
$$

Combining (17) and (18), the relationship among $P, a$ and $\gamma$ can be expressed by

$$
P A_{x} X^{\alpha}(Y-a+\gamma)^{\beta}-K A_{x} X^{\alpha}(Y-a+\gamma)^{\beta}+a+P A_{y} X^{\alpha}(Y-\gamma)^{\beta}=2 P_{0} Q_{0}
$$

Just as in (13), the relationship of $P, Q_{x}$ and $\gamma$ can be expressed by

$$
P Q_{x}-K Q_{x}+Y+\gamma-\left(\frac{Q_{1}}{A_{x} X^{\alpha}}\right)^{\frac{1}{\beta}}+P A_{y} X^{\alpha}(Y-\gamma)^{\beta}=2 P_{0} Q_{0}
$$

Also, as in (15), the relationship of $P, Q_{x}$ and $Q_{\mathrm{y}}$ is expressed by

$$
P Q_{x}-K Q_{x}+\left[Y+\left(Y-\left(\frac{Q_{y}}{A_{y} X^{\alpha}}\right)^{\frac{1}{\beta}}\right)-\left(\frac{Q_{x}}{A_{x} X^{\alpha}}\right)^{\frac{1}{\beta}}\right]+P Q_{y}=2 P_{0} Q_{0}
$$

Based on the model established above, we can analyze the mutual influence relations of $P, a$ , $\gamma, Q_{x}$ and $Q_{y}$, and further guide the external cost internalization of enterprises.

\section{Model verification and discussions}

\subsection{Case introduction}

A certain logistics enterprise of ChangChun provides distribution services, the main business being to transport headlights of cars for car factories. The enterprise has a staff of 200, with two million yuan operating investment, the annual freight volume is 46 million ton-kilometer. According to vehicle type, the operating fees are shown in Table 3.

Table 3. Operating Costs of the logistics enterprise

\begin{tabular}{cccc}
\hline Vehicle type & $\begin{array}{c}\text { Vehicle } \\
\text { number }\end{array}$ & $\begin{array}{c}\text { Freight rate in Full load } \\
\text { (yuan / per vehicle) }\end{array}$ & $\begin{array}{c}\text { Sharing costs } \\
\text { (yuan) }\end{array}$ \\
\hline 16 m Tractor and span carriers & 16 & 32307 & 25385 \\
16 m pallet carriers & 24 & 30753 & 22485 \\
16 m flat cars & 30 & 29643 & 20885 \\
21 m flat cars & 10 & 30309 & 26585 \\
\hline
\end{tabular}

In this paper, we take the average freight rate of the different type of trucks; the average freight rate is 0.59 yuan per ton $-\mathrm{km}$. The distance between area 1 and area 2 is $3000 \mathrm{~km}$, and a full load is carried from area 1 to area 2 . The packaging material, which is removed in area 2 , is returned to area 1. The transport mode is truck-load, with vehicles and transportation details shown in Table 4.

Table 4. Operation expenses of the enterprise 


\begin{tabular}{|c|c|c|c|c|}
\hline O-D & Vehicle type & $\begin{array}{l}\text { Freight } \\
\text { volume per } \\
\text { vehicle }(t)\end{array}$ & $\begin{array}{c}\text { Transport } \\
\text { turnover volumes } \\
\text { per vehicle (t.km } \\
\text { ) }\end{array}$ & $\begin{array}{c}\text { Annual total } \\
\text { transport } \\
\text { turnover volumes } \\
(\mathrm{t} . \mathrm{km})\end{array}$ \\
\hline \multirow{4}{*}{$\begin{array}{c}\text { Area } 1 \text { to } \\
\text { area } 2\end{array}$} & $\begin{array}{c}\text { 16m tractor and } \\
\text { span carriers }\end{array}$ & 3.5 & 10500 & 3024000 \\
\hline & $16 \mathrm{~m}$ pallet carriers & 3.5 & 10500 & 4536000 \\
\hline & $16 \mathrm{~m}$ flat cars & 3.3 & 9900 & 5346000 \\
\hline & $21 \mathrm{~m}$ flat cars & 4.5 & 13500 & 2430000 \\
\hline \multirow{4}{*}{$\begin{array}{c}\text { Area } 2 \text { to } \\
\text { area } 1\end{array}$} & $\begin{array}{l}16 \mathrm{~m} \text { tractor and } \\
\text { span carriers }\end{array}$ & 3.5 & 10500 & 3024000 \\
\hline & $16 \mathrm{~m}$ pallet carriers & 3.5 & 10500 & 4536000 \\
\hline & $16 \mathrm{~m}$ flat cars & 3.3 & 9900 & 5346000 \\
\hline & $21 \mathrm{~m}$ flat cars & 4.5 & 13500 & 2430000 \\
\hline
\end{tabular}

\subsection{Negative external costs accounting}

After computation, the air pollution cost is $1.2 Q \times 10^{-2}$ yuan, the traffic accident cost is $1.96 Q \times$ $10^{-2}$ yuan, the noise pollution cost is $16.29 Q$ yuan, and the traffic congestion cost is $1.78 \times 10^{-2} Q$ yuan. Eventually, according to (6), the total external cost of the enterprise is $16.33 Q$ yuan.

\subsection{Analyzing the Model}

According to negative external logistics cost quantitative calculations, enterprises can set freight rates reasonably, and the government can formulate appropriate environmental policies as well. This

According to the data of operation and benefits of the enterprise, we fitted out the production function of the enterprise, assuming that the technical level of the enterprise can be improved by $5 \%$ after implementing green logistics; then the value of $A_{y}$ became 1.05. Based on the negativeexternal-costs internalization model, corresponding functions are deduced and then discussed.

This paper mainly employs graphs to analyze the relationships among investments in green logistics, government subsidies, freight rate and the freight volumes of enterprises. In the graph, the full line represents 'government subsidizes first', and the dotted line represents 'enterprise operates first'.

4.3.1. Analysis of the relationships among freight rate $P$, capital input of green logistics $a$ and government subsidies $\gamma$.

When the freight rate $P$ stays the same, for an enterprise bearing relatively high external costs and to ensure the actual meaning of the function, we set the freight rate $P$ to be 17, 19 and 21 in the situation 'government subsidizes first', and take 5, 17, 19 and 21 as $P$ in the situation 'enterprise operates first'. Then the relationship between the investment in green logistics and government subsidies is shown in Figure 2. 


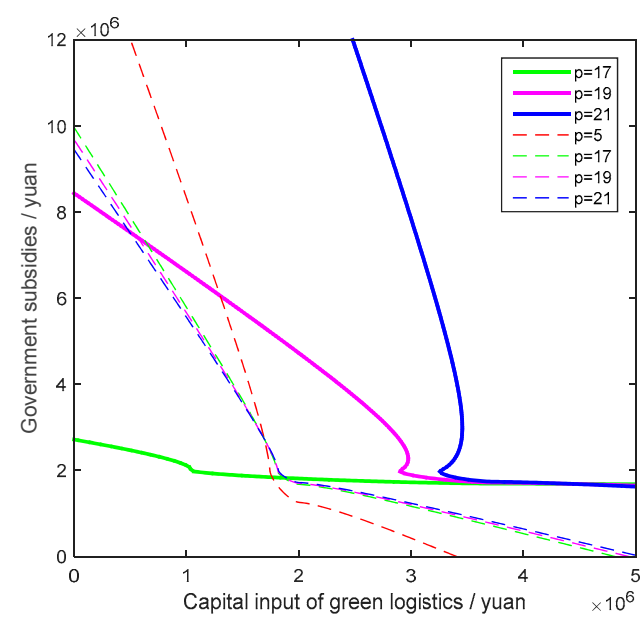

Figure 2.The Relationship between $a$ and $\gamma$ under certain $P$

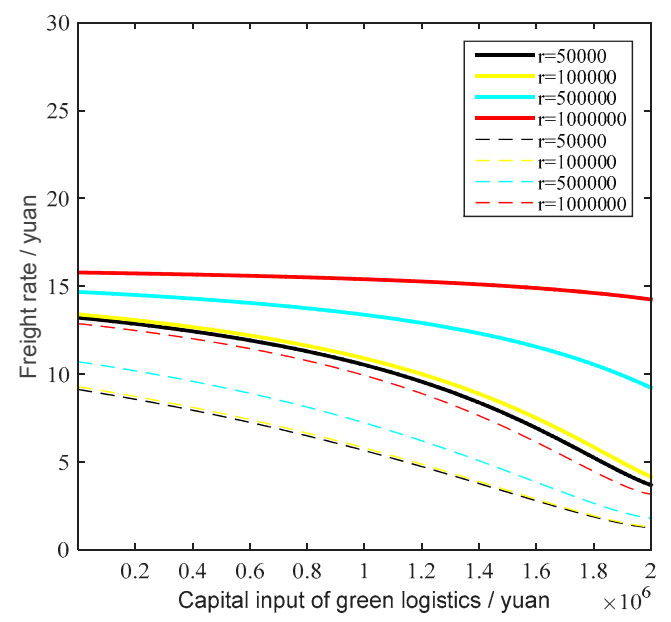

Figure 4. The Relationship between $a$ and $P$ under certain $\gamma$

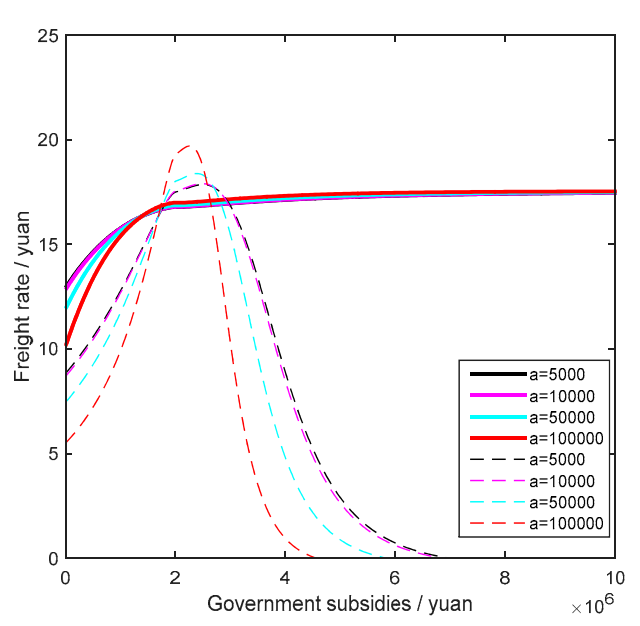

Figure 3. The Relationship between $\gamma$ and $P$ under certain $a$

From the curve tendencies for the two modes in figure 1, we know that market equilibrium can be achieved more quickly in the 'government subsidizes first' mode with lower freight rates. At the initial stage of achieving market equilibrium, enterprises have to bear all the negative external cost after the implementation of green logistics. This means the total cost of an enterprise is higher, thus the enterprise needs plenty of subsidies from government. But with the increase of capital invested in implementing green logistics, enterprise negative external costs are cut. And when the investment amount is reduced to the inflection point in the graph at a constant rate, the government subsidy rate will gradually slow with the increase in green logistics investment amounts. The result is that finally all enterprises in the market will implement green logistics and the government does not need to give subsidies or impose fines.

According to Figure 3, under the mode 'government subsidizes first', the freight rate changes faster in an early-stage market and tends to stabilize around 17, and the high freight rate is because of the high negative external costs. With the increase of government subsidies, the freight rate changes rapidly under the mode 'enterprise operates first', and if the government subsidies are low, the freight rate in the market will rise and stay higher. Otherwise, if the government subsidies increase to a certain point then the freight rate in the market will start to move down.

Figure 4 shows that when the government subsidies stay the same, the freight rate of the mode 'enterprise operates first' is lower on the occasion of the same investment in green logistics. In the mode 'government subsidizes first', there is more investment in green logistics when the freight rate 
stays the same. The figure can explained in this way: when the government subsidies stay the same, enterprises need to implement green logistics, so the freight rate in the market will rise to a higher level in a short time. With the improvement of green logistics investment, the technology of the enterprise improves as well, so the negative external cost of the enterprise reduces and the freight rate is gradually reduced.

4.3.2. Analysis of relationships among freight rate $P$, freight volumes of green logistics $Q_{x}$, and government subsidies $\gamma$.

According to Figures 5, 6 and 7, the fact that almost the same curve results in the two modes means that the relationships among freight rate, freight volumes and government subsidies are nearly the same. The curve's trend can be explained thus: as the negative external costs increase with the increase of transport freight volume, increased freight volume and high green logistics costs will lead to a higher freight rate and require more government subsidies.

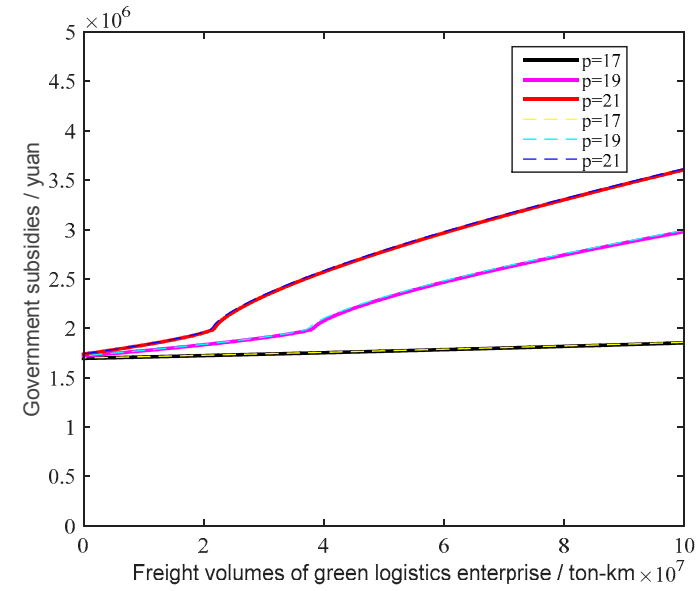

Figure 5. The Relationship between $Q_{x}$ and $\gamma$ under certain $P$

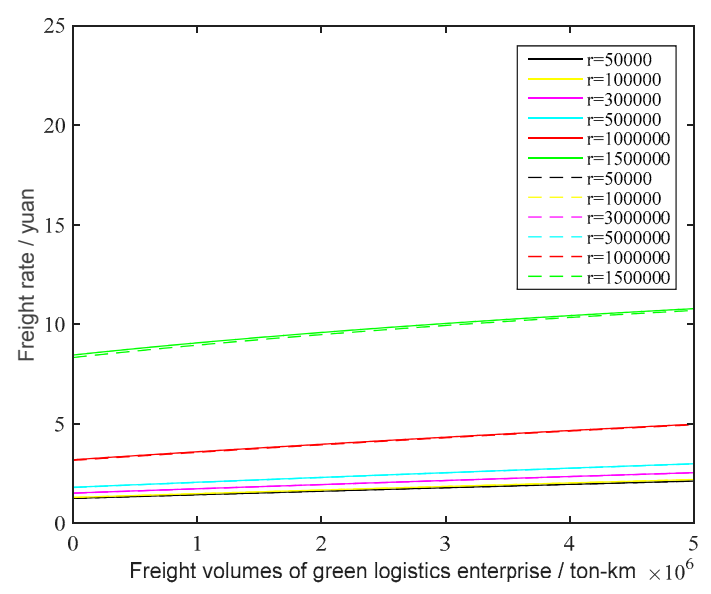

Figure 7. The Relationship between $Q_{x}$ and $P$ under certain $\gamma$

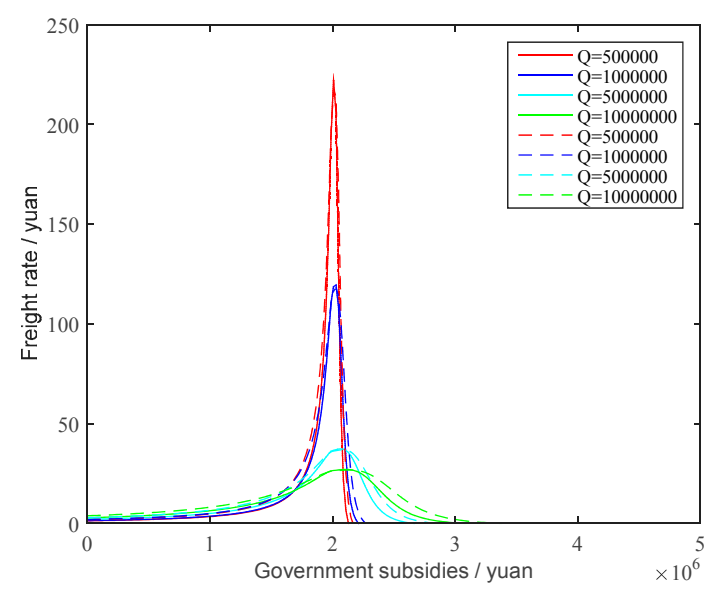

Figure 6. The Relationship between $\gamma$ and $P$ under certain $Q_{x}$

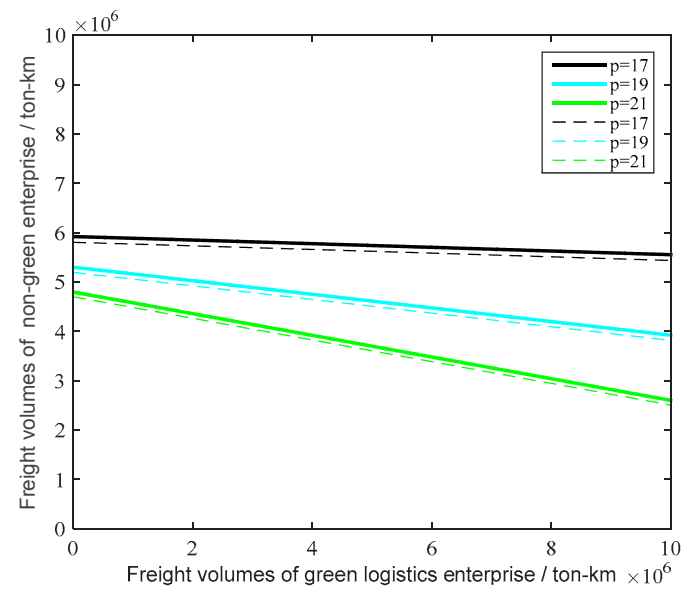

Figure 8. The Relationship between $Q_{x}$ and $Q_{\mathrm{y}}$ under certain $P$

4.3.3. Analysis of the relationships between freight rate $P$, freight volumes of green logistics $Q_{x}$ and freight volumes of non-green logistics $Q_{y}$

According to Figure 8, the changing trend of freight volumes of the two modes is the same, but the total freight volumes of the mode 'government subsidizes first' is larger. With the freight volumes of green logistics enterprises increasing, the freight volumes of non-green logistics enterprises are 
reduced. This means that if we expect more enterprises to implement green logistics, the government should subsidize more, so that the total freight volumes of green logistics enterprises can be improved.

\section{Conclusions}

The internalization of the negative external cost model, taking transportation enterprises as an example, compares many aspects, such as transport freight rates, the total amount of traffic, the cost of green logistics, and the rewards and punishment of government, and uses functions and graphics to analyze the interaction of all these factors clearly and intuitively. Combining the information of a logistics transportation enterprise, this paper calculates the negative external cost of the enterprise's logistics activities. Through the comparison of two incentive models 'enterprise operates first' and 'government subsidizes first', the model 'government subsidizes first' will have a more positive effect in promoting green logistics, and will be beneficial to the stability of the market freight rate. However, in this mode, the government's rewards and punishments cannot lower the transport freight rate enough, and the market freight rate will remain at a high level in the end. As for the effect of improving the green logistics enterprise's competitiveness, 'government subsidizes first' is better than 'enterprise operates first' because the negative external cost of logistics will be higher along with the freight volume, so that a large amount of money is needed to eliminate the negative externalities. With high government subsidies in the mode 'government subsidizes first', a green logistics enterprise will gain a higher return on investment because of higher overall investment. Last but not least, as the logistics negative externalities are difficult to eliminate thoroughly, green logistics enterprises can efficiently reduce their negative externalities by improving freight rates properly.

The model we established follows market economic patterns by calculating the negative external cost of logistics enterprises and clearly analyzing the relationships of the variables through graphs. Despite limitations, it still can provide an excellent basis for decision-making, both for enterprises and governments, when it comes to developing green logistics. As for the limitations, this paper has focused on transport enterprises, an approach that is representative, but has its limits. Because there exist a multitude of enterprises of different sizes and scales and business forms in the real market, it appears quite difficult to construct a model that fits all situations; more complex scenarios would require further research. Besides this, we can further consider the operational costs of the government in the process of regulation.

\section{References}

1. Johansson, B.; Mattsson, L.-G. Road pricing: theory, empirical assessment and policy. . Kluwer Academic Publishers: 1995.

2. Van Woensel, T.; Creten, R.; Vandaele, N. Managing the environmental externalities of traffic logistics: The issue of emissions. Prod Oper Manag 2001, 10, 207-223.

3. Kawase, R.; Matsuoka, Y.; Fujino, J. Decomposition analysis of co2 emission in long-term climate stabilization scenarios. Energy Policy 2006, 34, 2113-2122.

4. Jakob, A.; Craig, J.L.; Fisher, G. Transport cost analysis: A case study of the total costs of private and public transport in auckland. Environmental Science \& Policy 2006, 9, 55-66.

5. Lemp, J.D.; Kockelman, K.M. Quantifying the external costs of vehicle use: Evidence from america's topselling light-duty models. Transportation Research Part D-Transport and Environment 2008, 13, 491-504.

6. Lee, D.-H.; Dong, M.; Bian, W. The design of sustainable logistics network under uncertainty. Int J Prod Econ 2010, 128, 159-166.

7. Ubeda, S.; Arcelus, F.J.; Faulin, J. Green logistics at eroski: A case study. Int J Prod Econ 2011, 131, 44-51.

8. Marchet, G.; Melacini, M.; Perotti, S. Environmental sustainability in logistics and freight transportation. Journal of Manufacturing Technology Management 2014, 25, 775-811.

9. Lui, H. Distribution network design with considering externality. 2012, 1057-1060. 
10. Mesa-Arango, R.; Ukkusuri, S.V. Benefits of in-vehicle consolidation in less than truckload freight transportation operations. Transport Res E-Log 2013, 60, 113-125.

11. Havenga, J.; Simpson, Z. Reducing national freight logistics costs risk in a high-oil-price environment. The International Journal of Logistics Management 2014, 25, 35-53.

12. Lera-Lopez, F.; Faulin, J.; Sanchez, M.; Serrano, A. Evaluating factors of the willingness to pay to mitigate the environmental effects of freight transportation crossing the pyrenees. In 17th meeting of the euro working group on transportation, ewgt2014, Benitez, F.G.; Rossi, R., Eds. Elsevier Science Bv: Amsterdam, 2014; Vol. 3, pp 423-432.

13. Fumasoli, T.; Bruckmann, D.; Weidmann, U. Operation of freight railways in densely used mixed traffic networks - an impact model to quantify changes in freight train characteristics. Res. Transp. Econ. 2015, 54, 15-19.

14. Meersman, H.; Sys, C.; Van de Voorde, E.; Vanelslander, T. Road pricing and port hinterland competitiveness: An application to the hamburg-le havre range. Int. J. Sustain. Transp. 2016, 10, 170-179.

15. Baoqiang, X. Study on road transport emission based on externality theory. Master, Beijing jiaotong university, 2009.

16. Lindberg, G. Traffic insurance and accident externality charges. J Transp Econ Policy 2001, 35, 399-416.

17. Jing, D. Research on the calculation theory and method of the external cost of the transportation system in china. Master, Beijing jiaotong university, 2010.

18. Gang, Z.; Cong, L. Quantitative analysis and calculation of the negative externality of beijing transportation system. Ecological Economy 2014, 30, 57-63.

19. Hong, L.; Wenjun, L. Beijing-tianjin-hebei region transportation environmental cost assessment - based on the analysis of pollution loss method and the cost of environmental governance method. Price:Theory $\mathcal{E}$ Practice 2015, 52-54.

Conflicts of Interest: The authors declare no conflict of interest.

(C) 2016 by the authors; licensee Preprints, Basel, Switzerland. This article is an open access article distributed under the terms and conditions of the Creative Commons by Attribution (CC-BY) license (http://creativecommons.org/licenses/by/4.0/). 